\title{
METODOLOGIAS DE PESQUISAS COM CRIANÇAS
}

\author{
Altino José Martins Filho ${ }^{1}$ \\ Maria Carmem Silveira Barbosa ${ }^{2}$
}

\section{Resumo}

Este artigo diz respeito às escolhas teórico-metodológicas que procuram valorizar e tomar as crianças como sujeitos privilegiados nas pesquisas sobre a infância e a sua educação. A pretensão é abrir caminhos promissores na definição da participação das crianças pequenas nas pesquisas. $\mathrm{O}$ estudo demonstrou as polêmicas que geram controvérsias à participação das crianças nas pesquisas; evidencia-se que o crescimento de pesquisas com crianças aumentou a produção de conhecimentos sobre as infâncias, bem como o interesse em desenvolver metodologias e procedimentos não convencionais de pesquisas que qualifiquem as vozes das crianças.

Palavras-chave: Metodologia; crianças; pesquisa.

\section{Conhecer a infância: adultos pesquisando crianças pequenas}

\begin{abstract}
Estou sentado no parque com meu caderno de campo escrevendo a dinâmica dos movimentos das crianças e dos adultos. É uma tarde ensolarada e faz muito calor, o que torna as crianças agitadas e suadas com certa facilidade. Os adultos, quase todos na sombra de uma enorme árvore - uma linda abacateira, estão paralisados e conversando entre si. Apenas duas professoras sentadas com algumas crianças brincando e fazendo bolo para um simbólico aniversário. Percebo que nessa roda humana e calorosa,
\end{abstract}

\footnotetext{
${ }^{1}$ Doutorando em Educação - Estudos sobre Infâncias - pela Universidade Federal do Rio Grande do Sul/UFRGS(2009). Mestre em Educação - Educação e Infância - pela Universidade Federal de Santa Catarina/UFSC(2005). Tem experiência na área de Educação, com ênfase em Educação e Infância, pesquisando principalmente nos seguintes temas: Abordagens Teóricas em Educação Infantil; Prática Pedagógica; Culturas Infantis; Formação Docente em Educação e Infância.

2 Doutora em Educação pela Universidade Estadual de Campinas (2000), mestre em Educação pela Universidade Federal do Rio Grande do Sul (1987), especialista em Alfabetização em classes populares pelo GEEMPA (1984) e em Problemas no Desenvolvimento Infantil pelo Centro Lidia Coriat (1995). Atualmente é professora associada 1 da Universidade Federal do Rio Grande do Sul e atua no Programa de Pós-graduação - linha: Estudos da Infância.
}

Revista Reflexão e Ação, Santa Cruz do Sul, v.18, n2, p.08-28, jul./dez. 2010 
a aproximação das professoras contagia as sete crianças, entre bolos $e$ cantoria, um movimento harmônico entre adultos e crianças e entre as próprias crianças. Vemos uma alegria implacável. Estou escrevendo sobre a suposta festa de aniversário. Pois é algo que chama muito minha atenção. Num instante sou abordado por uma menina (de mais ou menos quatro anos). Ela sempre se interessa por meu diário de campo, quer desenhar nele e saber de minhas anotações. Mostra-se muito curiosa sobre o que escrevo. Ao se aproximar, me indaga: $O$ que escreves aí, Altino? Será que podes emprestar teu caderno para eu desenhar algo nele. Respondo: Claro, se você emprestar seu desenho para mim. Ele irá colorir o meu texto. A menina me olha seriamente e muito sorridente me diz: Deixo sim, sou uma menina muito "emprestativa” (Registro em diário de campo).

A princípio um diálogo cotidiano entre um adulto-pesquisador e uma criança num contexto de educação infantil. Mas precisamente uma menina de quatro anos que, muito curiosa, perspicaz e ainda pequena, já demonstra seu grau de autenticidade e protagonismo ao elaborar suas formas de socialização. O comportamento dessa menina coloca em xeque algumas certezas que construímos historicamente sobre as crianças e suas infâncias. Tal atitude e expressão de curiosidade dela têm nos perseguido e acompanhado durante esses últimos anos no exercício de desenvolvermos pesquisas com crianças pequenas. Talvez a simples resposta: Deixo sim, sou uma menina muito emprestativa; justifica nosso interesse em estudar as expressões próprias das crianças, aquilo que elas sabem e conhecem e que refletem na constituição das suas próprias relações sociais. Temos apostado seriamente nas respostas das crianças, naquilo que as constitui e no que elas constroem socialmente.

Análogo à interpretação da resposta dessa menina, procuramos indicar, localizar e anunciar o lugar que as crianças podem (e devem) ocupar nas pesquisas com a infância. Para nós uma possibilidade também de destacar o protagonismo infantil, que acompanha a necessidade de se desenvolver pesquisas que investiguem quem são as crianças, no sentido de conhecê-las melhor. O viés que perseguimos ultrapassa os limites de uma concepção descritiva sobre o desenvolvimento infantil, a qual se dá por etapas ou fases humanas, ou ainda, a ideia que compreende as crianças como simples 
sujeito a ser investigado, analisado ou interrogado. Sendo assim, surge no âmbito das pesquisas educacionais um tratamento científico às crianças pequenas, o que rompe com o esquecimento que as envolveu (ou envolve) na construção da história da própria infância.

Além da necessária participação ativa das crianças nas pesquisas, também estamos chamando atenção ao importante desenvolvimento de uma consciência político, pedagógica e teórico-metodológica em relação ao mundo social e cultural das crianças, principalmente, no que diz respeito à elaboração de princípios para a consolidação da própria constituição das crianças como sujeitos sociais ativos, deflagrando um projeto educacional e de práticas metodológicas não convencionais interligado aos anseios, desejos e necessidades das próprias crianças. Isto fortalece e preenche a defesa das crianças como atores sociais e sujeitos ativos nas investigações, pois lhes atribui uma relevância própria com participação direta durante a coleta dos dados nas pesquisas.

Este é o desafio teórico-metodológico posto para os adultos que querem pesquisar a infância e os conteúdos que ecoam das vozes das crianças. Em outras palavras, desafio para pesquisadores que pretendem analisar as culturas infantis e as formas de socialização das crianças, a partir de procedimentos metodológicos que, mesmo sendo definidos e utilizados por adultos, direcionam-se a colher das crianças por meio de suas vozes - o material empírico necessário às suas análises. Isto nos leva a querer aprofundar o conhecimento sobre a infância a partir das indicações das crianças, falar e ouvir sobre as experiências da infância e interpretá-las com a participação das mesmas. Consideramos esta a forma de (re)significar as hierarquias geracionais dos papéis sociais estabelecidos cultural e cientificamente. Como aponta Sirota (2001), trata-se de compreender aquilo que a criança faz de si e aquilo que se faz dela, e não simplesmente aquilo que as instituições (escola, Estado e família) inventam para ela. É 
nessa perspectiva que se fala do adultocentrismo como acúmulo de obstáculo ao conhecimento da realidade de ser criança. Adultocentrismo que se torna sombra nas pesquisas com a pequena infância, sombras que obscurecem as vozes das crianças.

Falar de adultos pesquisando crianças é alertar para a necessidade de um reverso científico, no qual é preciso

\begin{abstract}
abandonar uma técnica da palavra aculturante, e passar ao exercício de um ouvido refinado, numa perspectiva de mútua construção (...), [proporcionando] práticas de encontro com a fala das crianças, [estimulando] a leitura da realidade que elas, diretamente, nos oferecem (...) [permitindo] uma desinibição do ouvi-las (BECCHI, 1994, p.83).
\end{abstract}

O reverso que apontamos é o desenvolvimento de um olhar e de uma escuta atenta e sensível em um diálogo coletivo. Falamos da necessidade de olhar as crianças com uma "lente de aumento", a qual nos aproxima de suas vozes, ações, reações, manifestações e relações. A lente de aumento nos possibilitará ultrapassar o muro que isola a criança do adulto, muro firme que tem bases sólidas, pois foi construído ao longo da história da humanidade. Mas, que mesmo assim, pode ser rompido.

Nessa direção, a perspicácia da menina no excerto que abre nosso texto - "sou muito emprestativa" - nos possibilita abrir uma porta para considerar as crianças como sujeitos privilegiados nas pesquisas com a infância. Almeja-se que o diálogo teóricometodológico elaborado pelos adultos na construção de metodologias não convencionais com crianças, represente não apenas um esforço de pesquisa, mas uma aventura de sensibilidade e escuta aos mundos sociais e culturais das crianças.

\title{
metodológico
}

Criança fala de muitos jeitos: a escuta das crianças como procedimento

Podemos dizer que é muito nova entre pesquisadores a preocupação em desenvolver metodologias que levem o adulto a escutar o ponto de vista das crianças. De fato, a atitude que coloca o adulto na posição de captar das próprias crianças as 
peculiaridades e especificidades do mundo social da infância, é algo que tem motivado pesquisadores a querer conhecer o que elas pensam, sentem, dizem e fazem. Para tal, precisamos ainda superar o grande desafio de aprender a se relacionar respeitando os jeitos de ser das crianças. Destacamos a importância de construirmos mecanismos e estratégias metodológicas que nos aproximem das crianças pequenas, elaborando recursos férteis e procedimentos de interlocução entre as duas lógicas geracionais - dos adultos e das crianças - as quais são muito diferentes entre si, mas que estão entrelaçadas pela cultura e a produção da própria história. Ora, sabemos que ainda não dedicamos um tempo suficientemente necessário à observação das crianças e ao modo como elas produzem suas culturas, suas formas de socialização e suas maneiras de interpretação das coisas que vivem, experimentam, criam e recriam.

Contextualizando historicamente os procedimentos teórico-metodológicos de pesquisas com a infância, percebemos que as crianças não foram consultadas, olhadas, ouvidas e muito menos consideradas ${ }^{3}$. Na história da humanidade, as crianças não foram estudadas por seu próprio mérito (Qvortrup, 1999). Para a ciência, a racionalidade adultocêntrica era a que teria que prevalecer, a qual encerrou a possibilidade de escuta das vozes infantis. Nesse caso, o que seria indicado pelas crianças não teria cientificidade ${ }^{4}$, aumentando a disparidade de poder entre adultos e crianças nas pesquisas com a infância.

Considerando esse quadro, acreditamos que seja preciso ultrapassar o discurso esmagador legitimado historicamente pela razão adultocêntrica que até o momento alimentou as ciências humanas e sociais. Há a necessidade de enfrentar as polêmicas que

\footnotetext{
${ }^{3}$ No Brasil, encontramos um texto inédito na década de 1940, escrito por Florestan Fernandes, realizado no campo da sociologia da educação. Orientado pelo francês Roger Batisde, foi publicado em 1947 sob a denominação "As 'Trocinhas'do Bom Retiro".

${ }^{4}$ Isto também aconteceu com outros grupos humanos. Como exemplo podemos citar as mulheres, os índios, os negros, etc. Considerados como os "mudos da história". Porém, como podemos perceber e constatar, nunca se mantiveram silenciados, pois muito resistiram e contextualmente foram lutando por seu espaço. Neste caso, consideramos que as crianças, negros, índios e mulheres não foram os mudos da história, porém suas formas de resistências foram silenciadas.
} 
geram controvérsias em relação ao renovado respeito teórico-metodológico em pesquisas com crianças. Falamos do necessário enfrentamento aos desafios em querer desenvolver pesquisas com crianças e não sobre crianças. Isto permite ao pesquisador qualificar os diversos jeitos das falas das crianças, em pleno sentido de tomá-las como referentes empíricos nos estudos das infâncias. O que visa a conhecer as crianças a partir delas mesmas, ou seja, efetuar um exercício de observação, percepção, penetração, participação e interação no aqui e agora delas.

Tal abordagem pretende ultrapassar as barreiras disciplinares impostas às ciências humanas e sociais, principalmente no sentido de romper com o paradigma que considera o fenômeno infância como algo irrelevante e sem nada de especial (Ferreira, 2002, 2004). Isto tem proporcionado a consolidação de diálogos entre as diferentes áreas de conhecimentos e possibilitado aos pesquisadores da infância transitar entre os vários campos disciplinares. Em síntese, a evolução dos estudos e pesquisas sobre as infâncias e a educação das crianças em instituições de educação infantil tem correspondido ao próprio avanço das ciências humanas e sociais. Portanto, as fronteiras já foram desbravadas, agora é o momento de construir diálogos entre as duas lógicas socializadoras - adultos e crianças -, em um especial desejando localizar as crianças a partir de seus muitos jeitos de falar. Manuela Ferreira (2002) assevera que há necessidade de se conceptualizar uma condição de criança socialmente construída no dia a dia, na experiência de relação direta e implicada com outros - adultos e crianças, em contextos sociais específicos e diversos.

\footnotetext{
A assunção de critérios e valores próprios de pensar, sentir, dizer, saber e fazer, aprendidos e reproduzidos num quadro de relações sociais em contextos educativos, estável e durável, torna-os patrimônio cultural inerente ao grupo de crianças. Assim, são esses pensares, sentires, dizeres, saberes e fazeres, pela sua gênese, reconhecimento e partilha em atividades cotidianas coletivas que estruturam as culturas infantis (FERREIRA, 2002, p. 120).
} 
Nesse sentido é que falamos de uma criança que nos fala de muitos jeitos. Com base nessa crença a criança passa a ser compreendida como sujeito principal, em primeira mão, a dar informações aos investigadores. O que significa dizer que, são elas os sujeitos privilegiados para o pesquisador perguntar, observar, conversar, fotografar, filmar e registrar em suas pesquisas.

\section{Contextos e desafios teórico-metodológicos nas pesquisas com crianças}

Evidenciamos que a decisão de desenvolver práticas de metodologias que tomam as crianças como sujeitos participantes do processo não é algo simples. Ao contrário do que se pensa, mesmo estando diante de um movimento de pesquisas que inclui as crianças como sujeitos participantes do processo metodológico, o desenvolvimento de metodologias e procedimentos de pesquisa com crianças ainda é um campo incipiente. Isso pelo fato de que nós, adultos, necessitamos abrir mão de muito do que tradicionalmente afirmamos sobre os grupos infantis. Sarmento e Pinto (1997) esclarecem melhor esta questão:

\footnotetext{
O estudo das realidades da infância com base na própria criança é um campo de estudos emergente, que precisa adotar um conjunto de orientações metodológicas cujo foco é a recolha da voz das crianças. Assim, além dos recursos técnicos, o pesquisador precisa ter uma postura de constante reflexibilidade investigativa. (...) a não projetar o seu olhar sobre as crianças colhendo delas apenas aquilo que é o reflexo dos seus próprios preconceitos e representações. O olhar das crianças permite revelar fenômenos sociais que o olhar dos adultos deixa na penumbra ou obscurece totalmente. (SARMENTO \& PINTO, 1997. p. 78).
}

Não basta apenas dizer, é preciso desenvolver de maneira crítica e consciente que a participação das crianças envolve uma mudança na ênfase dos métodos e assuntos de pesquisas. Sendo assim, a relação entre adultos e crianças não pode seguir um viés de submissão e sim de mediação, interação e negociação. Portanto, o rompimento com o dualismo adulto-criança é a dimensão que gera um estatuto de emancipação ao sujeitocriança. Neste caso, para negociar é necessário construir formas de comunicação e 
participação com das crianças. As negociações marcam o traçado de um encontro que privilegia as crianças e as peculiaridades de sua categoria geracional. Em pesquisas com crianças pequenas, esse é o contexto que se quer deflagrar, pois é o desafio teóricometodológico mais emergente a ser encarado.

Com a idéia de detectar até que ponto adultos pesquisadores compartilham da participação das crianças nas pesquisas, ressaltamos quatro eixos essenciais a serem considerados nos estudos sobre os contextos e sobre os novos desafios teóricometodológicos:

$1^{\circ}$. A comunicação estabelecida entre adultos e crianças;

$2^{\circ}$. as negociações proporcionadas, construídas e consideradas pelos adultos;

$3^{\circ}$. as relações travadas com os sujeitos-crianças;

$4^{\circ}$. a forma de participação das crianças a partir das escolhas dos procedimentos metodológicos.

Tais eixos analisados em sua essência se constituem como porta de entrada para o desvelamento de algumas questões obscuras de pesquisas que acabam subestimando e subutilizando as informações das crianças. Ou ainda, pesquisas que acabam superestimando as crianças, que também é uma maneira de isolá-las do contexto real.

Nesse sentido, é fundamental aprofundar um ponto de equilíbrio no que se refere à participação de adultos e de crianças; no caso das crianças, se não é mais aceitável subestimá-las, também tem que se ter cuidado para não superestimá-las na escolha dos procedimentos metodológicos. Esta concepção provoca uma diferença nos estudos sobre as infâncias, pois se a criança é ativa, o adulto jamais será passivo e vice-versa. Por causa disso, as relações precisam ser descritas e consideradas dentro de uma possibilidade de reciprocidade. Isto ajuda a identificar a posição dos sujeitos nas investigações, mesmo quando se tem despertado o desejo de pesquisar os bebês.

O equilíbrio que buscamos estabelecer - entre adulto e criança - nos permite Revista Reflexão e Ação, Santa Cruz do Sul, v.18, n2, p.08-28, jul./dez. 2010 
romper com o autoritarismo ou com o espontaneismo impregnado nas metodologias de pesquisas. Isto poderá ajudar a construir a autoria de cada sujeito nas investigações. Essa concepção exige outras energias dos pesquisadores que se aventuram a adentrar no universo da infância, no sentido de conhecer as crianças.

Quinteiro (2004) afirma que os saberes constituídos com a infância que estão ao nosso alcance até o momento permitem-nos conhecer mais sobre as precárias condições sociais das crianças, sobre sua história e sua condição profundamente adversa de adulto em miniatura, e pouco sobre a infância como construção cultural, sobre os seus próprios saberes, as suas práticas e possibilidades de criar e recriar sua realidade social. Dessa forma nos perguntamos: afinal, o que sabemos sobre as culturas infantis? Como é que [as crianças] veem o mundo em que vivem e como é que veem a sua condição de ser criança? Que condições lhe são oferecidas para constituírem suas produções sociais? Em que medida as ações das crianças têm espaço dentro dos processos sociais?

As crianças se apresentam como sujeitos desconhecidos! Tomando esse pressuposto e buscando lançar um olhar sobre a infância na sua doce, tênue e forte complexidade (Kramer, 1996), podemos dizer que faz necessário o pesquisador ir além da mera descrição dos dados coletados. As descrições precisam ser preenchidas com a complexidade que reveste a infância. Desse modo, vale à pena insistir na ideia de visitar o mundo das crianças para torná-lo especialmente significativo e visível, o que pode contribuir para desnaturalizar o silêncio que circunda o envolvimento das crianças nos procedimentos metodológicos eleitos nas pesquisas. Concordando com Bastide (1979) dizemos que há entre o mundo dos adultos e o das crianças, como que um mar tenebroso, impedindo a comunicação. Navegar, ou ainda, arriscar-se a nadar neste mar, é como que se entregar aos "humores endoidecidos" das crianças. Neste sentido, é que reafirmamos que não basta observar as crianças de fora, como também não basta 
prestar-se a seus brinquedos; é preciso penetrar, além do círculo mágico que delas nos separa, em suas preocupações, suas paixões, é preciso viver o brinquedo (Bastide, 1979, p.154). Isto significa realmente ter como foco nas pesquisas a coleta das vozes, dos olhares, dos pensares, dos sentires, dos dizeres, dos saberes delas. Sem dúvida, tal atitude não constitui mero detalhe ou uma simples inovação, mas sim, pode determinar decididamente a maneira de o pesquisador olhar a criança, a infância e o próprio contexto sociocultural que a circunda. Interagir com os humores endoidecidos das crianças é ir além das aparências do fenômeno, é aproximar-se de sua essência. Cabe lembrar, com base em Marx (1978), que essência e aparência são produzidas pelo mesmo complexo social. Queremos dizer com isso que é preciso atravessar o mar tenebroso para estabelecer uma comunicação com as crianças, enfrentar a fúria do mar é (re)inventar outras formas de metodologias de pesquisas no âmbito das ciências humanas e sociais. É preciso navegar por mares nunca antes navegados, porém, sem perder de vista que é preciso ancorar em um porto que seja seguro para definir critérios sérios para o trabalho de pesquisas com crianças pequenas. Navegar sem naufragar é o desafio! Contextualizar a viagem faz a diferença.

\section{Procedimentos teórico-metodológicos eleitos em pesquisas com crianças: abordagens e tendências}

Estaremos destacando alguns procedimentos teórico-metodológico eleitos em pesquisas com crianças. Isto permite desatar os fios e descobrir novos desafios teóricometodológicos no que diz respeito às abordagens e as tendências em pesquisar diretamente as crianças por seu próprio mérito. Embora não seja objetivo deste trabalho realizar um levantamento minucioso das abordagens e tendências em seu amplo espectro, já que tal trabalho não corresponde ao objetivo deste texto, o que se pretende é 
realizar uma incursão em uma parcela da produção de pesquisas brasileiras $^{5}$ na possibilidade de descrever alguns aspectos gerais sobre o lugar da infância e de suas relações no que diz respeito às metodologias de pesquisas que vem sendo utilizadas. Desse modo, após ter a amostra definida, perguntou-se: as crianças são pesquisadas? Que lugar as diferentes infâncias ocupam nas pesquisas? Quais as metodologias utilizadas? O que já se tem construído e utilizado em termos de recursos metodológicos? Que procedimentos são eleitos em pesquisas com crianças?

Destacamos que as abordagens e tendências seguem estratégias de investigação optando preferencialmente por metodologias qualitativas e de cunho interpretativo. Os pesquisadores dizem que esta forma de pesquisar é uma possibilidade de analisar dados e fatos de forma abundante e que evidencia a riqueza dos detalhes do cotidiano. Portanto, buscam apontar nos estudos posicionamentos dialógicos com a realidade pesquisada. Talvez esta seja uma das indicações mais significativas que devemos perseguir e aprofundar atualmente. Há necessidade de conhecer e investigar temas que encontram-se abertos quando tratam do cotidiano. É necessário dar maior destaque e visibilidade à realidade das escolas, creches ou pré-escolas.

Os procedimentos teórico-metodológicos, eleitos a partir das pesquisas que analisamos, defendem o estudo do cotidiano como algo essencial para o desenvolvimento das ciências da educação. Nesse aspecto, afirmamos que é necessário que façamos uso de construções teóricas que consigam apreender analiticamente o que a vida nas instituições de educação reúne, desvelando as tramas reais que se armam a

\footnotetext{
5 A amostra da pesquisa foi composta por trabalhos apresentados na Associação Nacional de PósGraduação e Pesquisa em Educação/ANPED, especificamente no Grupo de trabalho Educação de Crianças de zero a seis anos/GT07. O período pesquisado compreende a última década 1999-2009. Na busca dos dados partimos do pressuposto segundo o qual as pesquisas têm trazido indicações epistemológicas, teórico-metodológicas, sociais, culturais e políticas que advogam um emergente conhecimento das crianças como crianças, dando eco as vozes da infância.
} 
partir de histórias cotidianas, em que se constrói a atividade educacional, social e cultural dos sujeitos pesquisados.

Nesse contexto foi possível identificar que a escolha da forma de pesquisar crianças tem sido em grande maioria o "estudo de caso". O qual é caracterizado como sendo um método que permite penetrar na realidade social e descrever a complexidade de um caso concreto, desvelando a multiplicidade de dimensões presentes numa determinada situação ou problema, focalizando-o como um todo. Em síntese, essa forma de pesquisa é definida como sendo um método propício para aprender os modos explícitos e implícitos dos sistemas simbólicos que regulam ou favorecem as relações, as manifestações, as ações, as formas de socialização e a produção das culturas infantis entre as crianças.

Coaduna-se com essa reflexão a crescente perspectiva que parte de um enfoque multidisciplinar e interdisciplinar para discutir as questões em torno da criança e da infância, rompendo com o tradicional domínio da Psicologia, principalmente a Psicologia Desenvolvimentista. A justificativa encontrada no material compilado, por um lado, impera na indicação de que para olhar os fenômenos da infância requer que o pesquisador transite pelas diversas áreas do conhecimento no sentido de "dar conta" de seus processos em suas múltiplas facetas e determinações. Por outro lado, este transitar pelas diferentes áreas, entra em convergência com os aportes teórico-metodológicos da Pedagogia da Infância, a qual vem ganhando importância e se configurando como campo de estudos da educação infantil, na última década.

Dentre o universo de contribuições das diferentes abordagens teóricometodológicas, o ponto de ancoragem da abordagem em maior escala é o do recente campo da Sociologia da Infância. Em escala decrescente aparecem ainda as seguintes abordagens: perspectiva dos autores italianos e abordagem histórico-cultural, 
principalmente no que diz respeito ao pensamento de Vygotsky e seus interpretes. Nesse contexto, tendências teórico-metodológicas de pesquisas vêm se formando e trazendo alguns destaques de temas. Em especial apresentamos as mais evidenciadas: práticas sociais concernentes às relações entre crianças e as delas com os adultos; relações de poder; adultocentrismo e subordinações de idade; infância plural; questões de gênero; produção das culturas infantis; brinquedo, jogo e brincadeira; os modos singulares de subjetivação das crianças; experiências cotidianas das crianças; as práticas de interação na creche sob o olhar das crianças; infância e natureza; criança indígena e suas especificidades; lógica de transgressão das crianças, crianças fora das creches ou pré-escolas e a alteridade da infância.

Na mesma direção, as pesquisas analisadas, na sua maioria, fazem referência à necessidade de considerar elementos como inserção social, cultura, etnia, religião, gênero, espaço geográfico e geração (Sarmento \& Pinto, 1997), pois tais dimensões vão construir diferentes jeitos de ser criança e viver a infância em cada momento histórico; enfim, definem a importância de singularizar as crianças com base no contexto em que estão inseridas, de não pesquisar a criança isoladamente, de forma asséptica, alheia a sua condição social.

Foram citados oito tipos diferentes de procedimentos metodológicos e ainda foram denominados de diversas formas. Igualmente a existência de uma multiplicidade de perspectivas teóricas, pelas quais são articuladas diferentes áreas de conhecimento na abordagem de seu objeto de estudo, há também uma quantidade significativa de trabalhos que utilizam mais de dois procedimentos metodológicos para coletar os dados empíricos junto às crianças. Constatamos que o cruzamento mais frequente foi a utilização simultânea do registro etnográfico, registro fotográfico, filmagens em vídeo, uso de desenhos das crianças e a observação participante. Há consenso nas pesquisas 
examinadas de que em investigação com crianças é necessário lidar com mais de um procedimento metodológico para compreender o fenômeno que se quer estudar. Nesse sentido, os trabalhos apresentados vêm intensificando uma diversidade de alternativas metodológicas que ultrapassam as formas tradicionais de pesquisar crianças. Diríamos, como Quinteiro (2000, p.112), que os novos procedimentos usados "formam um feixe que não se esgota e que apresenta inúmeras dificuldades para serem vencidas pelo pesquisador". Sumariamente apresentaremos algumas indicações referentes aos procedimentos de pesquisas com crianças que mais se destacaram nas pesquisas que analisamos.

O Registro etnográfico ou descrição densa - há forte tendência para o uso da etnografia em pesquisas com crianças. Considerando a natureza dessa metodologia, os autores dos trabalhos, em sua maioria, indicam, tal qual André (1999), a necessidade de adição de palavras como orientação, do tipo, de inspiração, de cunho, para situar a diferença entre fazer etnografia e utilizar essa ferramenta como um dos instrumentos de observação. Nota-se que em alguns estudos os autores são mais enfáticos, explicitando que em pesquisas educacionais não é possível levar ao "pé da letra" os preceitos clássicos da etnografia. Nesse caso, sublinham que, sem dúvida nenhuma, a etnografia contribui para estabelecer maneiras criativas de contato e interação com os sujeitos investigados. Em outros trabalhos, os pesquisadores anunciam que a utilização das estratégias do método etnográfico poderá ser um elemento fértil para permanecer no campo, para decifrar e anotar o modo que os pesquisados dialogam com a cultura contemporânea, ou ainda, para compreender de que maneira a cultura contemporânea se manifesta nos sujeitos investigados. Assim, advertem que o texto e o contexto são, para qualquer pesquisador, importantes ferramentas conceituais, e a etnografia importante 
recurso para realizar a leitura desse universo. É nessa perspectiva que se insere a utilização da etnografia em pesquisas com crianças.

O conjunto dos trabalhos que se utilizaram da etnografia indica o uso do caderno de campo, bloco de anotações ou, ainda, diário de bordo. A recomendação é escrever o que se vê e em casa, ao digitar as anotações, reorganizá-las tecendo alguns comentários que complementem o vivido. Existe igualmente um número significativo de trabalhos em que indicam ser necessário manter o registro etnográfico intacto e ao lado, em outra folha anexa, escrever as observações e as impressões. Nesse caso, quando for realizar a análise, o pesquisador coloca as duas folhas lado a lado para elaborar as interpretações. Tal exercício é indicado como sendo mais fidedigno com a realidade. Sendo assim, alertam que é importante não sucumbir à tentação de julgar o que se vai analisar, outrossim, é necessário tentar compreendê-la nos seus próprios termos.

O registro fotográfico - a fotografia nas pesquisas com crianças, mais do que um clic, é um importante recurso metodológico. O uso da fotografia ajuda a tomar posse das coisas transitórias que têm direito a um lugar nos arquivos da memória. Sendo assim, há uma possibilidade de se olhar para a imagem congelada, retratada pela foto, inúmeras vezes, um exercício pleno de ver e rever a cena, os personagens e o contexto. Tal possibilidade aguça a memória, a imaginação, a criação e a reconstituição da própria história vivida, pelas imagens e nas imagens. A fotografia mostra sempre o passado lido aos olhos do presente, embora já não seja o mesmo passado, mas sua leitura ressignificada. Diante disto, a leitura das imagens se apresenta como um instrumento de aproximação da realidade sócio-histórica e cultural do grupo fotografado. Portanto, mais do que ilustrar as seções do texto ou dar-lhe um "colorido", a fotografia reconstrói o próprio olhar do pesquisador, apresentando-se como outras possibilidades de escritas outros textos - da realidade estudada. 
A filmagem em vídeo - também é um recurso bastante utilizado em pesquisas com crianças. A utilização desse procedimento geralmente coincide com o uso do registro fotográfico. Dessa forma, o registro em vídeo vem contribuindo marcadamente na captação de imagens que revelam os diferentes jeitos de ser criança em suas peculiaridades, bem como a dinâmica do mundo cultural que circunda as (re)produções infantis presentes no contexto da instituição. $\mathrm{O}$ emprego da filmagem nas pesquisas é uma maneira de obter dados os mais próximos possíveis ao movimento das crianças, pois a imagem filmada e a sua transcrição, simultaneamente, articulam entre si a possibilidade de captar com maior expansão e expressão aquilo que não é perceptível à primeira vista.

Nesta direção, em nossas análises sinalizamos que a imagem captada espontaneamente pode traduzir uma situação que não se reproduz uma segunda vez; a filmagem traz algo diferente da observação e do registro escrito, pois o que a observação a olho nu muitas vezes não percebe ou deixa escapar, a filmagem capta com maior veracidade. Assim, afirmamos que, a cada cena assistida e revista existe a possibilidade de novas significações e novas interpretações. A filmagem, portanto, tornando-se uma memória audiovisual.

A observação participante - a observação participante ou a observação com participação tem sido o ponto forte nas pesquisas com crianças. Encontramos argumentações nas análises dos pesquisadores do tipo: - “em pesquisas com crianças é impossível observar sem participar, a observação é sempre com participação”. Também fica explicito que o pesquisador não tem como fugir da participação, já que as crianças estão o tempo todo pedindo e puxando os adultos para suas brincadeiras, interações, relações, produções, experimentos e diálogos. Os pesquisadores tornam-se um Outro, que observa e é também observado. Dessa forma, pesquisados e pesquisadores vão 
pouco a pouco estabelecendo e criando laços, o que favorece as relações e o desenvolvimento de uma participação sensível às produções das crianças. A observação participante possibilita o acesso dos adultos ao que as crianças pensam, fazem, sabem, falam e de como vivem, esmiuçando suas peculiaridades e as particularidades desse grupo geracional. Esta forma aberta e desprovida de amarras poderá aprofundar as heterogeneidades das infâncias.

O que se constata é que os pesquisadores realizavam suas observações em um período de dois a três dias por semana, durante, no máximo, oito meses de coleta de dados. As observações ocorriam em todo o contexto da creche, em que lhes era facultado participar e acompanhar diferentes momentos da vida em curso no espaço e tempo das instituições pesquisadas. Geralmente os pesquisadores se detinham em um grupo de crianças, porém contextualizando todas as relações no intuito de compreender as significações do universo estudado.

Desenhos das crianças - no conjunto das pesquisas analisadas, essa estratégia é tomada como importante recurso metodológico com crianças, embora aparecendo em menor proporção. O desenho infantil é considerado uma produção cultural das crianças e um instrumento revelador das representações infantis. A justificativa que mais aparece nos trabalhos em relação ao uso dos desenhos das crianças é que a iconografia representa uma possibilidade de reconstruir o espaço da creche como lugar da infância. Podemos firmar que, para além de simplesmente desenhar, é necessário elaborar uma interpretação dos desenhos a partir dos olhares e falas de seus autores - as crianças. $\mathrm{O}$ desenho é compreendido como atividade de criação e expressão humana. Nesse sentido, com a especificidade do desenho, aparece a consideração de quatro aspectos que o descrevem: o autor (a criança que o desenha), o próprio desenho em si, a fala do autor 
que o produz e o contexto em que ele é produzido. Esses aspectos, em se tratando de pesquisas com crianças, são essenciais para as análises.

Consentimento para fazer a pesquisa: em pesquisas com crianças a questão do consentimento é um dos grandes obstáculos que ainda temos que superar. O impasse é: a quem pedir o consentimento para realizar a pesquisa? $\mathrm{O}$ dos pais basta. $\mathrm{E}$ as crianças não precisam consentir ou exprimir sua recusa a participar das pesquisas. Se buscarmos construir procedimentos de pesquisas que atribuem às crianças a condição de sujeitos sociais, não seriam elas as primeiras pessoas a serem consultadas para a realização das pesquisas? Embora não seja ainda possível um consenso para essa questão, podemos fazer algumas ponderações a partir das metodologias das pesquisas analisadas. Parece que é unânime a autorização dos familiares para se realizar pesquisas com crianças pequenas. Também o compromisso do pesquisador em informar os familiares sobre o andamento dos estudos e organizar uma exposição na instituição com as fotos que serão analisadas. Em relação às crianças, já existem pesquisas que sinalizam a importância de pedir a autorização destas para a utilização de suas fotografias.

O necessário afastamento da realidade: muitas das pesquisas descrevem a importância do professor no papel de pesquisador se afastar de suas atividades profissionais durante o período da coleta de dados e análise dos mesmos. Isto contribui decisivamente no estranhamento da realidade, limpando-se dos vícios que por ventura lhes acompanham. Martins Filho (2005) comenta em seu trabalho que o afastamento das atividades de professor de crianças pequenas foi fundamental para que pudesse perceber e questionar a realidade e as relações que eram estabelecidas - estranhar o cotidiano é preciso, afastar-se da realidade para ler os dados é essencial. Acrescenta, ainda que o redimensionamento da pesquisa só foi possível após seu distanciamento como professor do cotidiano da creche. 
Nesse sentido que consideramos importantíssimo trazer e aprofundar as questões dos procedimentos metodológicos, já que concordamos que eles ocupam um lugar central e decisivo em qualquer investigação. O método escolhido passa a iluminar todos os passos no caminhar da pesquisa, ou seja, é o método que vai determinar o próprio percurso da pesquisa.

\title{
METHODOLOGY OF RESEARCH WITH CHILDREN
}

\begin{abstract}
This paper is concerned to the theoretical and methodological choices that seek for valuating and taking the children as privileged subjects in researches about childhood and education. The intention is to open promising ways on defining participation of small children in researches. The study demonstrated the polemics on the researches of children in researches, it is evidenced that the research growth with children has increased the knowledge production about the childhood as well as the interest in developing unconventional methodologies and procedures of research that qualify the children's voices.
\end{abstract}

Keywords: Methodology; children; research.

\section{Referências}

ANDRÉ, Marli Eliza D. A. de. Etnografia da prática escolar. Campinas (SP): Papirus, 1999. (Série Prática Pedagógica)

BARBOSA, Maria Carmem Silveira. Por amor e por força: as rotinas na Educação Infantil. Tese (doutorado) - Universidade Estadual de Campinas, Faculdade de Educação. Campinas: 2000. 
BARBOSA, Maria Carmem Silveira. Educação infantil na Itália: quatro publicações da Editora Artes Médicas. In: Pro-posições. Revista da Faculdade de Educação/UNICAMP, v. 10, n. 1 (28), p.195-197,1999.

BASTIDE, Roger. Prefácio. In: FERNANDES, Florestan. Folclore e mudança social na cidade de São Paulo. Petrópolis, Vozes, 1979. p. 153-155.

BECCHI, Egle. Por uma pedagogia do bom gosto. Campinas, SP: Autores Associados, 1994.

DEMARTINI, Zeila de B. Fabri. Infância, Pesquisa e Relatos Orais. In: Faria, Ana Lúcia de; DEMARTINI, Z. de B. F.; PRADO, Patricia D. (Orgs.). Por uma cultura da infância: metodologias de pesquisa com crianças. Campinas, SP: Autores Associados, 2002.

DELGADO, Ana Cristina \& MÜLLER, Fernanda. Sociologia da Infância: pesquisas com crianças. In: Educação e Sociedade: Revista de Ciências da Educação. Vol. 26, mai/ago. São Paulo: Cortez, 2005.

FARIA, Ana Lúcia G. de. Educação Pré-Escolar e Cultura. $2^{\text {a }}$ Ed. Campinas, SP: Editora da Unicamp; São Paulo: Cortez, 1999.

FERREIRA, Maria M. Martinho. A Gente Aqui o que Gosta mais é de Brincar com os Outros Meninos: as crianças como atores sociais e a (re)organização social do grupo de pares no quotidiano de um Jardim de Infância. Doutorado em Ciências da Educação. Faculdade de Psicologia e Ciências da Educação, Universidade do Porto, 2002.

FERREIRA, Maria Manuela Martinho. Do "avesso" do brincar ou... as relações entre pares, as rotinas da cultura infantil e a construção da(s) ordem(ens) social(ais) instituintes(s) das crianças no jardim-de-infância. In: SARMENTO, Manuel Jacinto \& CERISARA, Ana Beatriz. Crianças e miúdos: perspectivas sociopedagógicas da infância e educação. Edições ASA- Porto- Portugal 2004.

FERNANDES, Florestan. As 'Trocinhas' do Bom Retiro. Folclore e Mudança Social na cidade de São Paulo. Vozes: Petrópolis, 1947.

JOBIM E SOUZA, Solange. Re-significando a psicologia do desenvolvimento: uma contribuição crítica à pesquisa da infância. In: KRAMER, Sônia, LEITE Maria Isabel. Infância: fios e desafios da pesquisa. São Paulo/Campinas: Papirus, 1996. p. 39-55.

KUHLMANN JR. Moisés. Infância e educação infantil: uma abordagem histórica. Porto Alegre: Mediação, 1998.

MARTINS, José de Souza. (org.) Regimar e seus amigos: a criança na luta pela terra e pela vida. In: MARTINS, José de Souza. O massacre dos inocentes. São Paulo: Hucitec, 1993.

MARX, Karl. A ideologia alemã. Tradução Dutra, Waltensir. Rio de Janeiro: Zahar, 1974. 
MARTINS FILHO, Altino José. Crianças e adultos na creche: marcas de uma relação. Dissertação de Mestrado - UFSC. p.185, 2005.

MARTINS FILHO, Altino José. A vez e a voz das crianças: uma reflexão sobre as produções culturais na infância. In: Presença Pedagógica. n.61, p.35-45, jan./fev. Belo Horizonte, 2005.

MARTINS FILHO, Altino José. O lugar da criança. Pátio Educação Infantil, ano 6, $\mathrm{n}^{\mathrm{o}} .17$, p. 10-13, jul/out 2008.

MARTINS FILHO, Altino José (Org.). Criança pede respeito: temas em educação infantil. Mediação: p.160. Porto Alegre, 2005.

MARTINS FILHO, Altino José (Org.). Infância plural: crianças do nosso tempo. Mediação, p.160. Porto Alegre,2006.

QUINTEIRO, Jucirema. Infância e escola: uma relação marcada por preconceitos. Campinas. Tese (Doutorado em Educação) Faculdade de Educação da UNICAMP, São Paulo, 2000.

QVORTRUP, Jeans. A infância na Europa: novo campo de pesquisa social. Centro de documentação e informação sobre a criança. Instituto de Estudos da Criança, Universidade do Minho. Tradução de Helena Antunes, 1999.

ROCHA, Eloisa A. Candal. A Pesquisa em Educação Infantil no Brasil: trajetória recente e perspectiva de consolidação de uma Pedagogia da Educação Infantil. Florianópolis, Centro de Ciências da Educação, Núcleo de Publicações, 1999.

SARMENTO, Manuel J. \& PINTO, Manuel. As crianças e a Infância: definindo conceitos delimitando o campo. In: PINTO, Manuel \& SARMENTO, Manuel J. (Orgas.). As Crianças: Contextos e Identidades. Braga, Portugal: Centro de Estudos da Criança, 1997.

SARMENTO, Manuel J.. Sociologia da Infância: correntes, problemáticas e controversas. Sociedade e Cultura. Cadernos do Noroeste, Série Sociologia, v.13, n.2, p. 145-164, 2000.

SARMENTO, Manuel J.. A infância: paradigmas, correntes e perspectivas (mimeo). Florianópolis, 2001.

SIROTA, Régine. Emergência de uma Sociologia da Infância: evolução do objeto e do olhar. Cadernos de Pesquisa, São Paulo, nº 112, pp.7-31, mar. 2001.

VYGOTSKY, L. S. Obras Escogidas vol. III. Madrid: Centro de publicaciones del MEC y Visor Distribuiciones, 1995. 